\title{
Tecnologia e Conhecimento - Pessoas e Protagonismos: um relato de experiência extensionista
}

\author{
Silvana Maria Carbonera ${ }^{1}$, Andreia de Jesus ${ }^{1}$, \\ Alexander Robert Kutzke ${ }^{1}$ e Izabel do Rocio Costa Ferreira ${ }^{1}$
}

${ }^{1}$ Setor de Educação Profissional e Tecnológica

Universidade Federal do Paraná

Curitiba - PR

\{andreia.jesus, alexander, izabel.ferreira, silvana.carbonera\}@ufpr.br

\begin{abstract}
The purpose of this article is to describe the actions and activities carried out in the first edition of the University Extension Project "Building Knowledge with the Use of Technology", from the Professional and Technological Education Sector, Federal University of Paraná. Its main purpose of the Project is to promote the conscious use of technology in educational processes, in the school environment, to cope with and overcome vulnerabilities. At the end of the first year of the Project, it is verified that access to digital technologies and literacy in such an aspect are insufficient for the Digital Social Inclusion of the social actors of the public school in the region of Curitiba, as it is also necessary to develop skills and competences with respect to the use of these technologies and knowledge to use them with security, ethics and autonomy.
\end{abstract}

Resumo. $O$ objetivo deste artigo é descrever as ações e atividades realizadas na primeira edição do Projeto de Extensão universitária "Construindo Saberes com o Uso de Tecnologia”, do Setor de Educação Profissional e Tecnológica, da Universidade Federal do Paraná. O Projeto tem por principal finalidade promover o uso consciente da tecnologia em processos educativos, no ambiente escolar, para enfrentamento e superação de vulnerabilidades. Finalizado o primeiro ano de realização do Projeto, constata-se que o acesso a tecnologias digitais e o letramento em tal aspecto são insuficientes para a Inclusão Socio digital dos atores sociais da escola pública da região de Curitiba, pois é necessário também desenvolver habilidades e competências com relação ao uso dessas tecnologias e conhecimento para utilizá-las com segurança, ética e autonomia.

\section{Introdução}

Um docente e estudantes. Uma sala de aula, um quadro verde, giz, às vezes uma televisão, um projetor, um rádio. Uma cena que pode ser colocada, historicamente, em vários momentos que perpassaram o Século XX, em ambientes que vão da Educação Básica ao Ensino Superior. Todavia, ao chegar ao Século XXI, um outro elemento passa a fazer parte da cena acima descrita, representado por outras tecnologias que ganham espaço na vida e na sala de aula dos atores que a integram. 
VIII Congresso Brasileiro de Informática na Educação (CBIE 2019)

Anais do XXV Workshop de Informática na Escola (WIE 2019)

Questões surgem: permitir ou proibir o uso do celular em sala de aula? Banir? Resistir ou torná-lo aliado? E o computador? É mais uma plataforma de jogo ou pode ser um aliado no ambiente escolar? Afinal, a tecnologia é uma ferramenta ou é uma ameaça ao que já se sabe fazer em sala de aula? Como o uso de tecnologias pode afetar as relações entre as pessoas e contribuir, de forma positiva ou negativa, com a formação dos estudantes e docentes? E como os usuários da tecnologia estão tratando os efeitos jurídicos de seus atos?

Provocados pelas questões acima, docentes do Setor de Educação Profissional e Tecnológica da Universidade Federal do Paraná, oriundos de várias áreas - Informática, Saúde e Direito -, reunidos no Grupo de Pesquisa "Educação e Tecnologia: Pessoas e Protagonismos", em conjunto com o GEPTA - Grupo de Estudos e Pesquisas em Tecnologia Aplicada", com a parceria da ONG "Instituto Tecnologia e Dignidade Humana" e sob a coordenação da Prof.a Ms. Andreia de Jesus, estruturaram este Projeto de Extensão que tem por objetivo tratar de alguns aspectos relacionados tanto às questões postas acima quanto identificadas junto à comunidade escolar do Colégio Estadual Santa Rosa, localizado no bairro do Cajuru, no município de Curitiba, Paraná, local onde o Projeto está sendo realizado desde 2018 .

Tal projeto, intitulado "Construindo Saberes com o uso de Tecnologia $-1^{a}$ edição", cuja área temática é a Educação, com foco nas linhas de extensão "Metodologia e estratégias ensino/aprendizagem", "Mídias" e "Grupos sociais vulneráveis", assenta na premissa de que a promoção do uso da tecnologia em processos educativos, no ambiente escolar, contribui diretamente para o enfrentamento e para a superação de vulnerabilidades pessoais e sociais, tornado seus atores mais autônomos.

A produção do conhecimento, neste sentido, é uma das variáveis que pode contribuir para fortalecer a pessoa na medida em que lhe permite desenvolver condições de aquisição e fortalecimento de autonomia pessoal, com respeito à singularidade e dignidade individual. Conhecer e usar a tecnologia, de forma consciente, neste processo de fortalecimento é uma ferramenta indispensável na medida em que permite que as pessoas não sejam colocadas à margem de uma história que tem na presença marcante da tecnologia nas relações sociais um elemento importante.

Para tanto, o ambiente escolar é um espaço privilegiado na medida em que permite, para além da produção do conhecimento formal, também tratar de questões que possam contribuir diretamente para o enfrentamento da vulnerabilidade social. Tal vulnerabilidade pode ser compreendida como a exposição de pessoas, ou de grupos sociais, a variados riscos (econômicos, culturais, sociais), o que acaba expondo-as a diferentes desafios para seu enfrentamento [Monteiro 2011, p. 32].

A efetivação do Projeto, programada para ser realizada entre 2018 e 2021, assenta nos seguintes objetivos:

1. Incentivar o uso consciente das Tecnologias da Informação e Comunicação (TIC's) tanto em sala de aula quanto em outros espaços sociais;

2. Ofertar formação continuada aos docentes do ensino fundamental, médio, técnico e/ou EJA (Educação de Jovens e Adultos), com relação ao uso consciente e responsável de tecnologias no processo de ensino-aprendizagem;

3. Ofertar formação complementar aos discentes do ensino fundamental, médio, 
VIII Congresso Brasileiro de Informática na Educação (CBIE 2019)

Anais do XXV Workshop de Informática na Escola (WIE 2019)

técnico e/ou EJA, com relação ao uso consciente e responsável das tecnologias;

4. Possibilitar o empoderamento do indivíduo, por meio do uso consciente e responsável das tecnologias, com relação às temáticas sobre saúde, educação e direto;

5. Possibilitar a construção do protagonismo pessoal ou coletivo, nos diversos contextos e grupos sociais relacionados de forma direta ou indireta ao contexto escolar.

Constata-se a relevância da proposta na medida em que o sentido de extensão universitária, compreendido como “(...) um processo interdisciplinar, educativo, cultural, científico e político que promove a interação transformadora entre Universidade e outros setores da sociedade" [FORPROEX 2012, p. 15] torna-se realidade, integrando a Universidade e o conhecimento científico nela produzido à Sociedade para a produção de conhecimento e de transformação social.

Sob tal perspectiva, a integração do conhecimento universitário com o conhecimento popular propicia fomentar uma concepção freireana de Universidade, ou seja, uma Universidade democrática, comprometida com as problemáticas da comunidade/sociedade e fomentadora de transformações sociais [Gadotti et al. 2008].

Importante salientar que o processo de integração entre Sociedade e Universidade apresentado neste relato foi estruturado a partir dos cinco princípios que orientam a atividade extensionista, quais sejam: (1) a Interação Dialógica, (2) a Interdisciplinaridade e a Interprofissionalidade, (3) a Indissociabilidade entre Ensino-Pesquisa-Extensão, (4) o Impacto na Formação do Estudante e (5) o Impacto e Transformação Social, a partir da articulação de quatro áreas diferentes de conhecimento, quais sejam, educação, saúde, direito e tecnologia.

\section{Método}

As atividades do projeto de extensão "Construindo Saberes através do uso do Computador - $1^{a}$ Edição", desenvolvidas ao longo do ano de 2018 junto ao Colégio Estadual Santa Rosa, foram estruturadas da seguinte forma:

Na FASE 1, foi realizada a divulgação das atividades do projeto junto às comunidades interessadas, com a realização de uma palestra de apresentação da proposta de atividades do Projeto no Colégio Estadual Santa Rosa, Instituição de Ensino participante. Houve, também, a divulgação do projeto aos estudantes do Setor de Educação Profissional e Tecnológica e com a inscrição e seleção de voluntários e bolsistas interessados em atuar no projeto.

Como resultado de tais atividades, engajaram-se ao projeto seis estudantes do Curso Superior de Tecnologia e Análise e Desenvolvimento de Sistemas, sendo que dois deles atuaram como bolsistas de extensão e quatro foram voluntários. Tais estudantes participaram de todas as atividades do projeto. Além disso, dois outros estudantes do Curso Superior de Tecnologia em Gestão de Qualidade participaram como colaboradores, atuando na aplicação de avaliação e na análise dos resultados de uma das atividades realizadas.

A Fase 2 consistiu no processo de formação dos acadêmicos que participaram do projeto, bolsistas e voluntários, com a realização de oficinas e palestras, ofertadas pelos 
VIII Congresso Brasileiro de Informática na Educação (CBIE 2019)

Anais do XXV Workshop de Informática na Escola (WIE 2019)

docentes envolvidos, com o objetivo de prepará-los para atuarem nas atividades realizadas no Colégio Estadual Santa Rosa. Para tanto, foram formados grupos de estudos para a sistematização e preparação das atividades que foram realizadas no colégio. Tais atividades foram orientadas pelos docentes que participam dos Grupos de Pesquisa parceiros, integrando pesquisa acadêmica e extensão universitária, contando ainda com a participação do Instituto Tecnologia e Dignidade Humana, ONG parceira no projeto, que contribuiu diretamente com a reflexão sobre o uso consciente de tecnologias. Como resultado desta fase, os estudantes foram divididos em subgrupos de trabalho conforme as temáticas trabalhadas, realizaram leituras, estudos e discussões de artigos técnicos relacionados a elas e elaboraram material para aplicar nas atividades realizadas no Colégio.

A Fase 3 compreendeu a execução das atividades programadas no colégio, feita pelos estudantes, com a orientação dos docentes envolvidos, bem como com a realização das avaliações. Foram realizadas três atividades, todas tendo como fio condutor a construção de saberes com o uso da tecnologia e com o objetivo de inclusão sócio digital. A primeira delas foi representada pela execução de um curso de extensão denominado "Reforçando os laços de convivência entre gerações por meio do uso do smartphone e suas tecnologias", cujo objetivo principal foi fortalecer a convivência entre gerações, permitindo a troca de experiências entre adolescentes estudantes no Colégio, avôs e avós, contribuindo para a inclusão da pessoa idosa e para o exercício de cidadania de parte dos estudantes do ensino fundamental do Colégio. A segunda atividade consistiu no Uso do Celular em Sala de Aula, realizado na disciplina de ciências, com as turmas do $7^{\circ}$ e $8^{\circ}$ anos, que trataram respectivamente do tema Invertebrados e do Sistema Nervoso, e na disciplina de Artes, com o $8^{\circ}$ ano, realizando um Vídeo Arte.

A terceira atividade, tendo como referência o Uso Consciente das Tecnologias, desenvolveu duas atividades elaboradas pelos acadêmicos envolvidos. Num primeiro momento, foi realizado um Ciclo de Palestras dirigidas aos estudantes do $6^{\circ}$ ao $9^{\circ}$ anos, que tratou dos seguintes temas: Ergonomia Física e o Uso das Tecnologias; As Tecnologias e as Relações Sociais; Impactos das Tecnologias no Aprendizado. Num segundo momento, foi realizada uma oficina de Hardware básico, na qual foram apresentados os componentes básicos de um computador, sua montagem e configuração, com os objetivos de proporcionar aos estudantes tanto a compreensão do funcionamento do equipamento quanto habilitá-los a realizar pequenos consertos em suas máquinas domésticas.

A Fase 4 do projeto ocorreu de modo concomitante com as Fases 2 e 3, com duas atividades realizadas. Uma delas consistiu na produção de material, realizada tanto por parte dos acadêmicos, com o material utilizado para implementar as atividades no Colégio, como por parte dos docentes envolvidos, com a produção do relatório final e deste relato. A outra atividade consistiu na análise das avaliações realizadas. Para a atividade "Reforçando os laços de convivência entre gerações por meio do uso do smartphone e suas tecnologias", tendo como base a metodologia de avaliação por competências, foi aplicado um questionário, elaborado e analisado pelos estudantes colaboradores, e cujos resultados serão apresentados em artigo específico. Para a atividade que tratou do uso de tecnologias, verificou-se o despertar de uma visão crítica por parte dos estudantes do colégio em relação ao tema, especialmente tornando tal uso mais consciente por parte dos estudantes. Com as avaliações tornou-se possível propor ajustes das atividades e/ou novas atividades para a segunda edição do projeto. 
VIII Congresso Brasileiro de Informática na Educação (CBIE 2019)

Anais do XXV Workshop de Informática na Escola (WIE 2019)

E na Fase 5 houve a apresentação dos resultados do primeiro ano do projeto, realizado com o III Seminário do GEPTA, Grupo de Estudos e Pesquisas em Tecnologia Aplicada, um dos grupos de pesquisa parceiro do projeto. Com a atividade, foi possível comunicar ao público o estágio de desenvolvimento e resultados das atividades de Pesquisas e Extensão realizadas por alunos e docentes do grupo GEPTA e do Grupo Educação e Tecnologia: Pessoas e Protagonismos. Além disso, os resultados foram apresentados no $17^{\circ}$ ENEC - Encontro de Extensão e Cultura da UFPR, que ocorreu em 2018.

A realização das atividades acima descritas alcançou um público aproximado de 400 pessoas, compreendidas aqui tanto estudantes, docentes, técnicos e comunidade próxima do Colégio Estadual Santa Rosa, quanto estudantes e docentes do Setor de Educação Profissional e Tecnológica da UFPR.

O envolvimento entre as duas comunidades, ponto de partida do Projeto de Extensão, pressupôs a presença da Universidade dentro do Colégio, o que foi tornado possível com a intervenção e a colaboração de sua direção. Com isso, as atividades que envolviam o público do ensino fundamental foram todas desenvolvidas no ambiente escolar.

Dificuldades materiais surgiram ao longo da $1^{a}$ edição do Projeto. Quando houve a programação das atividades, realizada em conjunto com a equipe do Colégio, o laboratório de informática estava em uso, de modo que sua utilização foi planejada para várias atividades. Todavia, ao longo do ano, houve um problema técnico que inviabilizou sua utilização o que fez com que o curso "Programação de Computadores para Crianças" fosse inviabilizado. Já para a oficina de Hardware Básico, foram levados equipamentos emprestados da UFPR.

Outro ponto que se revelou frágil foi a rede WIFI do Colégio, que não conseguiu suportar o acesso simultâneo de vários equipamentos, não permitindo que todos os estudantes realizassem as atividades com o celular ao mesmo tempo. Esta questão foi resolvida dividindo a turma em grupo, de modo que todos os estudantes, em um ou noutro momento, pudessem realizar as pesquisas on line, realizando a atividade.

Independente de tais questões, foi possível realizar grande parte das atividades planejadas, cujos resultados serão apresentados a seguir.

\section{Resultado e discussões}

A realização das atividades do Projeto de Extensão "Construindo Saberes com o uso do Computador" ao longo do ano de 2018 no Colégio Estadual Santa Rosa resultou em um grande aprendizado para todos os agentes envolvidos.

Em se tratando dos acadêmicos, voluntários ou bolsistas, é possível constatar que, no âmbito da formação profissional, eles tiveram a oportunidade de colocar em prática os ensinamentos das disciplinas de Introdução à Arquitetura de Computadores, Comportamento Organizacional, Interação Humano Computador e Redação Técnica, ministradas no Curso Superior de Tecnologia em Análise e Desenvolvimento de Sistemas, SEPT/UFPR.

No âmbito acadêmico, os estudantes aprenderam a pesquisar e elaborar, com a orientação dos docentes participantes no Projeto, material para orientar o uso, em sala de aula, de aplicativos em celular, além de produzirem artigos científicos. 
VIII Congresso Brasileiro de Informática na Educação (CBIE 2019)

Anais do XXV Workshop de Informática na Escola (WIE 2019)

Em termos de cidadania, os acadêmicos contribuíram, de forma direta, para o desenvolvimento de um projeto sócio digital em um ambiente escolar. E, de forma não planejada, tiveram que resolver problemas inesperados quando, diante da impossibilidade posterior do uso do laboratório de informática, tiveram que adequar o que havia sido planejado para tornar exequíveis as propostas de atividade.

Em se tratando dos atores do Colégio Estadual Santa Rosa, ganhos também podem ser observados.A realização de atividades pensadas a partir da necessidade de temas relacionados à inclusão sócio digital, identificada junto ao público escolar, estudantes, docentes e técnicos, atendeu, de forma direta, a questões decorrentes do quotidiano daquele ambiente escolar. O processo de inclusão digital, realizado por meio da construção de conhecimento, ampliou o olhar dos estudantes que, habitualmente, utilizavam dispositivos disponíveis para comunicação em rede social ou para jogos. A título de ilustração, a utilização do celular para a realização de pesquisa escolar possibilitou aos estudantes que participaram de tal atividade a percepção prática de outros usos para uma ferramenta que já está inserida no quotidiano deles.

Em relação ao corpo docente, como atividade preparatória para a implantação do Projeto, o Grupo de Pesquisa "Educação e Tecnologia: Pessoas e Protagonismos" ofertou um curso de extensão aos docentes do Colégio que tratou de uso de recursos digitais em sala de aula. Tal curso, ofertado na modalidade semipresencial, teve por justificativa possibilitar a preparação prévia dos docentes para atividades do Projeto de Extensão que utilizariam tecnologia em sala de aula.

E como este relato refere-se a um Projeto de Extensão, é importante destacar que ele também atendeu aos cinco princípios extensionistas apresentados na introdução, articulando-os com as atividades realizadas, como se pode observar a seguir.

Em se tratando de Impacto e Transformação, possibilitou que acadêmicos da universidade compartilhassem seus conhecimentos técnicos com os atores do Colégio (direção, pedagogos, professores e alunos) e, através dessa socialização, contribuíram com novas atividades para o processo de ensino-aprendizagem do colégio, além de proporcionar uma experiência profissional aos acadêmicos.

No âmbito da Interação Dialógica, criou condições para a troca de saberes entre acadêmicos e os atores escolares, em que o primeiro compreende as problemáticas do ambiente escolar e o segundo compreende como a integração com pessoas que tenham conhecimento técnico da área de computação pode contribuir para a solução desses problemas.

Com o caráter Interdisciplinar, tornou-se possível a integração entre profissionais e acadêmicos da área de computação e informática com profissionais da área da educação e, desta forma, integrou ambos os conhecimentos o que promoveu atividades relacionadas a Informática na Educação, com caráter educacional, acadêmico e social.

Com a Indissociabilidade entre Ensino, Pesquisa e Extensão, o projeto possibilitou aos acadêmicos a prática do ensino e aprendizado de sala de aula, estendendo-se os conhecimentos acadêmicos à sociedade, neste caso, através do projeto de extensão em um ambiente escolar. Além disso, as experiências vivenciadas no projeto contribuíram para a identificação de objetos de pesquisa na área da Informática na Educação, os quais poderão ser estudados e pesquisados nos Grupos de Pesquisa do Setor de Educação Profissional e 
VIII Congresso Brasileiro de Informática na Educação (CBIE 2019)

Anais do XXV Workshop de Informática na Escola (WIE 2019)

Tecnológica da UFPR envolvidos no Projeto de Extensão.

Por fim, verifica-se o Impacto na Formação dos Estudantes pois o Projeto de Extensão, voltado à inclusão socio digital, contribuiu para que acadêmicos da área de Computação e Informática pudessem sistematizar e desenvolver metodologias de trabalho relacionadas a aplicação da informática na solução de problemas e na formação de pessoas para o uso consciente do computador e da internet. Além disso, projetos como este promovem a conscientização social desses acadêmicos, no que diz respeito a compreensão da importância deles para a sociedade com relação a inclusão sócio digital.

\section{Considerações finais}

O Projeto de Extensão acima apresentado tem na busca da integração de conhecimento dos atores envolvidos um de seus focos fundamentais. Ou seja, articular o conhecimento técnico, produzido na Universidade, ao conhecimento produzido no ambiente escolar e social é uma de suas bases.

Um segundo aspecto relevante consiste na integração de diversas áreas do conhecimento, um fio condutor que perpassa todo o planejamento e execução das atividades junto à comunidade escolar, na qual o projeto está sendo desenvolvido.

Por fim, importante destacar que o uso de tecnologias, especialmente da informática, para a construção do conhecimento é um aspecto essencial para a execução dos objetivos do Projeto, visto que o conhecimento é uma ferramenta que dá condições de emancipação e autonomia às pessoas.

Neste sentido, já foi possível constatar que as ações já realizadas permitiram aos participantes uma modificação de postura e de ação individual em relação a uso de tecnologia, deixando o papel de simples usuário para passar a agir, num primeiro momento, como usuário consciente das tecnologias disponíveis. Tem-se, com isso, o início de um percurso rumo ao protagonismo individual de todos os agentes participantes, na medida em que o conhecimento produzido com as atividades do Projeto passa a informar as ações quotidianas de tais pessoas.

Por tal razão, enfrentar questões trazidas pelas transformações tecnológicas foi uma das escolhas para orientar todas as ações do Projeto, o que foi realizado com o incentivo do uso consciente das TIC's disponíveis, sejam elas articuladas a questões de saúde, jurídicas ou outras que contribuam para que as pessoas alcançadas pelas ações do projeto, tanto no ambiente universitário quanto no escolar, possam construir sua autonomia enquanto cidadã e cidadão. Importante destacar que isso tornou-se possível pela estreita articulação entre este projeto e os grupos de pesquisa (Grupos de Pesquisa do Setor de Educação Profissional e Tecnológica da UFPR) que o sustentam, numa clara e necessária interação entre ensino, pesquisa e extensão universitária.

Além disso, os Parâmetros Curriculares Nacionais [Brasil 2000] salientam que aprender a utilizar a tecnologia diz respeito a compreender e utilizar o conhecimento científico-tecnológico. Em outras palavras, trata-se de aprender a fazer um uso consciente das tecnologias disponíveis.

E para além disso, o uso da tecnologia na educação não deve ser encarado apenas como uma inovação tecnológica, ou seja, um recurso a mais para ser utilizado em sala de aula. É necessário saber como os novos recursos tecnológicos podem contribuir para 
VIII Congresso Brasileiro de Informática na Educação (CBIE 2019)

Anais do XXV Workshop de Informática na Escola (WIE 2019)

a mudança da educação, pois, com as transformações que a tecnologia, de forma geral, provoca na sociedade, a escola precisa mudar, não só os conteúdos, mas também aceitar novos elementos que possibilitem a integração do estudante ao mundo que o circunda.

Devido a isto, os atores escolares devem tomar consciência não somente do uso pedagógico que as TIC's podem proporcionar, mas obter conhecimentos sobre os equipamentos e metodologias de uso dessas tecnologias, para que seja possível uma inserção efetiva nessa sociedade circundada de informações e equipamentos tecnológicos em constante evolução.

Observa-se, portanto, que a inclusão socio digital ganha papel de destaque na sociedade, pois não basta apenas ter acesso às tecnologias digitais e ser alfabetizado digitalmente, é preciso também desenvolver habilidades e competências com relação ao uso dessas tecnologias e conhecimento para utilizá-las com segurança, ética e autonomia, tornando-se assim um letrado digital.

Revela-se, portanto, o fundamento da parceria entre a Universidade, produtora e sistematizadora de conhecimento, e Instituições de Educação Básica, que necessitam de mecanismos para fomentar, nas suas atividades didático-pedagógicas, a Inclusão socio digital.

\section{Referências}

Brasil (2000). Parâmetros curriculares nacionais. http: / / portal . mec.gov.br/ seb/arquivos/pdf/14_24.pdf. Acesso em 17 junho de 2019.

FORPROEX (2012). Fórum de pró-reitores de extensão das universidades públicas brasileiras. política nacional de extensão universitária. http://www. renex.org.br; /documentos/2012-07-13-Politica-Nacional-deExtensao.pdf. Acesso em 17 junho de 2019.

Gadotti, M., Freire, P., and Guimaraes, S. (2008). Pedagogia: diálogo e conflito. Editora Cortez, $3^{a}$ edition.

Monteiro, S. R. d. R. P. (2011). O marco conceitual da vulnerabilidade social. Sociedade em Debate, 17(2):29-40. 